\title{
Extraction and Optimization of Natural Dye from Asphodellus tenufolium
}

\author{
Sangeeta Deo $^{1 *}$, Smriti Rekha Sarkar ${ }^{1}$ and Savita Kumari ${ }^{2}$ \\ ${ }^{1}$ Department of Textile and Apparel Designing, College of Community Science, DRPCAU \\ PUSA, India \\ ${ }^{2}$ College of Community Science, DRPCAU PUSA, India \\ *Corresponding author
}

\section{A B S T R A C T}

\begin{tabular}{l} 
K e y w o r d s \\
$\begin{array}{l}\text { Asphodellus tenufolium, } \\
\text { Non-allergic, Tassar Silk }\end{array}$ \\
Article Info \\
$\begin{array}{l}\text { Accepted: } \\
12 \text { October } 2018 \\
\text { Available Online: } \\
10 \text { November } 2018\end{array}$ \\
\hline
\end{tabular}

Keywords

Asphodellus tenufolium Non-allergic, Tassar Silk

Article Info

Accepted:

Available Online

\begin{abstract}
Although plants exhibit a wide range of dyes, not all of these pigments can exhibit as dyes. Jangali Pyaz commonly known as vanpyaz (Asphodellus tenufolium) is a weed plant which is shredded off as a waste was exploited as a source of natural dye for Tassar Silk with objective of standardizing conditions of extraction and dyeing, fastness properties, ecofriendliness and colour absorption. The optimum dyeing conditions were $4 \mathrm{~g}$ concentration, 60 minutes extraction time and 75 minutes of dyeing time. All the samples dyed with Jangli Pyaz with different mordants showed fairly good to very good washing and rubbing fastness. The colour gamut of Tassar Silk samples dyed with Jangli Pyaz indicated a red yellow one and the metal complexes (mordants) shift the colour of the dye. The dyed samples ranged from light peach to candy pink and grey with different mordants.
\end{abstract}

\section{Introduction}

The use of non-allergic, non-toxic and ecofriendly natural dyes on textiles has become a matter of significant importance due to increased environmental awareness in order to avoid some hazardous synthetic dyes. To save the world, there is a call "to go back to nature" and patronize natural products. There is also a move to find renewable resources to supplant the need to deplete our global assets and this thought has led to research into the production of natural dyes on commercial scale. Natural dyes obtained from vegetable sources are known as vegetable dyes/ eco-friendly dyes. Natural dyes are colourants with application in textiles, printing inks, food drugs, cosmetics and paint industries. Natural dyes mainly used on textiles are extracted from plants and minerals. Dyeing with natural dyes is a traditional craft of India. Until the later half of the $19^{\text {th }}$ century, almost all the dyes were vegetable or animal one in origin. Also known as vegetable dyes, these are made from various plant roots, leaves, tree bark, flowers and fruit rind.

There are mainly 500 plant species in India that yield colour (Gulrajani, 1999). The use of natural dyes went into oblivion with the invention of synthetic dyes in 1856 . The major breakthrough in synthetic dyes came with German chemist, Peter Grier's discovery of the diazo reaction and the azo group of synthetic dye based on diazo reaction proved to be most versatile. Of late, i.e. 1990 
onwards, Researchers had shown that some of the azo dyes are carcinogenic and get absorbed through skin. Germany that discovered the azo dyes became the first country to ban the import of certain azo dyes in 1996. The popularity of synthetic dyes had destroyed the traditional dye market in India. Chemical dyes are cheaper to manufacture but prove expensive. It is difficult to dispose the waste water containing residue of synthetic dyes. Disposal of waste water from natural dyes is not a problem. Water used for making dyes is just thrown into fields. It has organic content and is safe for fields. In addition to synthetic dyes other than prohibited dyes, 'vegetable dyes' are included under permitted dyes for use on organic and green textiles. Some natural (vegetable) dyes cannot only impart unique and elegant colours but also provide anti-bacterial and uv protective functions to the fabric. Thus it is of immense importance to explain the new sources of natural dyes which are available in plenty and hitherto to waste materials such as weeds which does not have food or economic value. It has been reported that any organic material can produce colour when boiled, but only certain plants will yield a colour that will act as a dye. In India and Bihar in particular is endowed with wealth of natural flora and fauna which provides the basic resources for natural dyes. There is ample scope to explore and revive application of natural dyes on textiles, having more and more scientific knowledge base. These natural dyes are widely distributed in rural belt can be a source of livelihood to traditional dyers and weavers. Organic dyeing not only helps to preserve the traditional art but also provides rural employment. In order to explore more and more new sources of natural dye, weed was used for exploring dye.

Asphodellus tenufolium also known as jangli pyaz is a notorious weed. It is a serious weed of rabi crops. It is postulated that before the wheat is planted, some weed had germinated which has to be uprooted at the time of planting. It is a annual herb and seeds are diuretic. This plant is eaten as raw or cooked during the time of famine. This weed plant which is shredded off as a waste, can be exploited as a source of natural dye on Tassar silk. Tassar silk of Bhagalpur, was used in this present study for innovative dyeing with natural dyes as this silk industry needs to be promoted in present day competitive world through value addition.

The objectives of this study were to extract natural eco-friendly dye from Asphodellus tenufolium, standardizing conditions of extraction and dyeing, testing its colour fastness, eco-friendliness and colour absorption

\section{Materials and Methods}

\section{Collection of raw material}

Bulbs of weed plant Asphodellus tenufolium commonly known as Jangli Pyaz were collected from the field of Rabi crops. The bulbs of plants were shade dried and were crushed to powder form. Tassar silk for the present study was purchased from khadi gramudog, Pusa. To confirm the nature of fibres it was tested as below:

\section{Burning test}

A small tuft of fibres was ignited. The fibres burnt readily giving odour of burning hair and left behind crushable ash confirming it to be silk fibres.

\section{Chemical test}

Fibres dissolved in hot concentrated solution of caustic soda, concentrated sulphuric acid, nitric acid and hydrochloric acid dissolved the silk fibre. 


\section{Specifications of the fibres}

\section{Weave}

The silk fabric used for the present research had plain weave.

\section{Fabric count}

It was determined by linen tester by counting the number of threads in one inch square in the warp and weft directions.

\section{Weight}

Five specimens of size $5 \mathrm{~cm} \times 5 \mathrm{~cm}$ were conditioned for 24 hours at room temperature over saturated common salt solution in desiccators.

\section{Thickness}

It was determined by fabric thickness tester. Various specifications of the fabric are given in Table 1.

\section{Degumming of silk}

The natural gum present in the silk hinders the dyeing process and hence it needs to be degummed. Degumming was carried out as per BIS method IS 970-1980.

\section{Wetting}

The samples of silk were soaked in water half an hour before being mordanted or dyeing for even penetration.

\section{Extraction of dye}

The extraction of dye from Jangali Pyaz was carried out by dissolving in water for 24 hours prior to extraction by boiling. The dye was extracted in different media; -aqueous, acidic and alkaline. Since the absorbance was maximum in acidic medium so it was selected for extraction during this study.

\section{Optimisation of dyeing conditions}

To optimize the variables of dyeing the tassar silk samples were dyed at different concentration of dye material, extraction time and dyeing time.

\section{Optimum concentration of dye material}

Five different concentrations1, 2, 3, 4 and $5 \mathrm{~g}$ per $1 \mathrm{~g}$ of silk samples were soaked in $100 \mathrm{ml}$ of distilled water each for 24 hours.

Dye solutions were extracted by boiling above solutions for 1 hour on water bath making up the solution $100 \mathrm{ml}$ as and when required. After the boiling, solutions were sieved and absorbance was measured. Dyeing was carried out in above extracted dye solutions for 1 hour.

After completion of dyeing, absorbance of the solutions were again measured on spectrophotometer. Dye absorption was calculated as.

Absorbance before dyeing Absorbance after dyeing Percent dye absorption = ------------- X 100

Absorbance before dyeing

\section{Optimum time for extraction of dye}

The optimum concentration as determined above was added to five beakers containing $100 \mathrm{ml}$ of water and kept for 24 hours. It was boiled and extraction was carried out for 30 , $45,60,75$ and 90 minutes separately.

Dyeing was carried out and percentage dye absorption was determined by measuring absorbance before and after dyeing to find out the optimum time of extraction. 


\section{Optimum time of dyeing}

The optimum amount of dye material was taken in five beakers separately and dye was extracted at optimum extraction time. Tassar silk samples were added in five dye solutions and dyeing was carried out for $30,45,60,75$ and 90 minutes to determine the optimum time of dyeing.

\section{Post treatment}

The dyed fabric samples were kept in salt solution $20 \mathrm{~g} / 100 \mathrm{ml}$ of water for one hour for dye fixation. The dyed fabric was then washed in non-ionic detergent 50pl at 60 degree centigrade for 20 minutes.

\section{Mordant}

The terms mordant is derived from the Latin word 'Mordere' which mean to bite or 'to hide of.' The mordant seems to bite into the fibre, making it possible for the dye to penetrate. The mordant is a metallic salt which can be an organic or an inorganic substance. The most commonly used inorganic mordants are salts of aluminium, chromium, iron and tin.

The mordant has affinity both for the fibre and the dye. These dyes which do not have any affinity for the fibre can be applied by using the mordant. The use of mordant increases the fastness properties by forming an insoluble compound of the dye with the mordant. A mordant fixes the dye in the fabric. It also helps to produce a colour and make the colour bright and fast. A mordant has a direct effect on the dye and governs the colour produced from a dye. The same dye produces different colour if used with different mordant. Mesta, calyx dye produced different colour such as pink, pinkish brown and violet with alum, copper sulphate and stannous chloride (Katyayini and Jacob, 1998). Pretreatment or post treatment with mordants is especially needed with natural dyes to have range of shades. The most common basic mordants are the salts of alum $\left(\mathrm{AlK}\left(\mathrm{SO}_{4}\right) \cdot 12 \mathrm{H}_{2} \mathrm{O}\right)$, the chemical name is potassium aluminium sulphate. Potassium dichromate $\left(\mathrm{K}_{2} \mathrm{Cr}_{2} \mathrm{O}_{7}\right)$ make a bright orange solution if exposed to light, this solution become unstable, so it should be kept with a lid on the container and not exposed to light. The (stannous chloride and stannic chloride) iron (ferrous sulphate) and copper (copper sulphate) out of these, copper and chrome are red listed and have been restricted to some stipulated limits by various eco-labels. The mordants used for the present study were of laboratory grade. The concentrations used were as follow:

Alum - 10\%

Copper Sulphate - 0.5\%

Ferrous Sulphate - $0.6 \%$

Chrome - $0.5 \%$

Stannous Chloride - 1.0\%

\section{Mordanting techniques}

Three mordanting methods viz., Premordanting, simultaneous mordanting and post mordanting methods were used for the present work.

\section{Premordanting}

In this method tassar silk samples were mordanted in the first stage and then dyed in the second stage.

\section{Simultaneous mordanting}

In this method mordant and the dye was applied simultaneously in the same dye bath. Dye liquour was boiled and then required amount of mordant was added and the silk samples were put in the dye bath and dyeing continued for optimum dyeing time. Samples were thoroughly washed, rinsed and dried in shade. 


\section{Post mordanting}

In this method silk samples were first dyed and then mordanted. First of all dye solution was prepared and silk samples were dyed at optimum dyeing conditions. A aqueous solution was prepared by adding required amount of mordant and then the silk samples were put in the mordant solution. It was boiled for about 30minutes. Samples were then washed, rinsed and dried in shade.

\section{Fastness properties of dyed materials}

Fastness properties are of utmost importance to textile consumers as there are many external factors or conditions which can affect its colour, such as washing, rubbing, light etc. So the dyed fabrics may be tested for their colour fastness properties as per the use of textiles fabric.

Fastness of dyed or printed textiles denote the resistance the fabric opposes to the varying or losing its shades to the action of various agents such as light, washing, rubbing, perspiration which can give rise to loss/change of shade and staining of the other textiles materials.

\section{Colour fastness to washing}

This method determines the effect of washing on the colour of textiles. The washing fastness was determined as per the test (IS 687: 1979). The dyed samples were evaluated for the change in colour and the degree of staining of the two pieces of the adjacent fabrics with the help of grey scales.

\section{Colour fastness to light (Sunlight)}

It was determined by the method of IS 6861985. In this method the specimens were exposed to day light and the fastness was accessed by comparing the change of colour.

\section{Colour fastness to rubbing}

Rubbing fastness was determined as per IS 766: 1988 test method. The rubbing fastness was carried out in dry as well as wet conditions. Assessment of test fabrics was carried out for the staining of the rubbing cotton cloth with grey scale for evaluating dry and wet staining.

\section{Colour measurement and co-ordinates}

The colour strength, $K / s$ values and $L^{*}, a^{*}, b^{*}$ co-ordinates were measured using premier colour scan instrument.

\section{Results and Discussion}

\section{Optimized variables}

Optimization is a very important technique for dyeing the fabric and is carried out to make the dyeing process more effective. It helps to choose the optical parameters for further process.

\section{Optimum concentration}

The percent dye absorption of tassar silk samples dyed at different concentration of dye material with dye materials extraction time for one hour and dyeing time of one hour are given in Table 2.

The data shows that when the concentration of dye material was increased from 1.0 to $2.0 \mathrm{~g}$, dye absorption increased from 20 percent to 35 percent respectively. When dye material concentration was further increased to $3 \mathrm{~g}$, dye absorption increased further to 40 percent, Dye absorption increased to 47 percent with further increase in dye materials concentration to $4 \mathrm{~g}$. When dye material concentration was further increased to $5 \mathrm{~g}$ percent dye absorption remained constant at 47 percent. It indicated that $4 \mathrm{~g}$ dye material concentration was the 
optimum concentration of Jangli Pyaz dye powder for Tassar silk samples.

\section{Optimum extraction time}

Taking $4 \mathrm{~g}$ the optimum concentration of Jangli Payz dye material, extraction was done at different times. The percent dye absorption of silk samples with optimum concentration of dye material extracted at different extraction time and dyed for one hour are given in Table 3.

Table 3 shows that percent dye absorption increased with increase in extraction time from 30 minutes to 60 minutes

Percent dye absoption was 32, 52 and 69 percent at 30, 45 and 60 minutes of extraction times respectively. Percent dye absorption was maximum at 60 minutes of extraction time. Percent dye absorption decreased after optimum time of extraction; 60 minutes. Percent dye absorption was 60 percent at 75 minutes of extraction time and 32 percent at 90 minutes of extraction time.

Thus it was concluded that 60 minutes was the optimum time for extraction of dye material for jangli pyaz dried powder taking optimum concentration of $4 \mathrm{~g}$ (Table 3 ).

\section{Optimum dyeing time}

Taking $4 \mathrm{~g}$ optimum concentration of dye material, extraction of dye material was carried out for 60 minutes (optimum time for extraction), the dyeing was carried out at different times, i.e. 30, 45, 60, 75 and 90 minutes respectively to find out the optimum dyeing time.

The percent dye absorption at different dyeing times, keeping the dye material concentration and extraction time optimum at $4 \mathrm{~g}$ and 60 minutes respectively are given in Table 4 .
Data (Table 4) shows that when dyeing was carried out for 30 minutes, percent dye absorption was 36 percent, when the dyeing time further increased to 45 minutes, percent dye absorption raised to 41 percent. With further increase in dyeing time to 60 minutes, percent dye absorption was 44 percent. When the dyeing was carried out for 75 minutes, dye absorption was maximum, i.e. 47 percent. Dye absorption remained constant beyond this. Thus the optimum dyeing time for Jangli Pyaz was 75 minutes for Tassar silk fabric.

\section{Properties of dyed material}

Table 5 shows the washing, light and rubbing, fastness of the dyed sample with different mordants. A dye molecule has two principal chemical group viz chromophores and auxochrome. The chromophores usually an aromatic ring is associated with the colouring property. It has unsaturated bonds whose number decided the intensity of colour.

\section{Washing fastness}

It is evident from the data given in Table 5 that dyed silk samples mordanted with alum, stannous chloride, ferrous sulphate, copper sulphate and chrome exhibited slight change in colour and negligible staining on adjacent fabrics. Stannous chloride and ferrous sulphate mordanted silk samples exhibited rating of 3 and all the other mordanted samples alum, copper sulphate and chrome exhibited rating of $4 / 5$ which is highly acceptable.

Staining on adjacent fabrics for silk dyed samples for copper sulphate and chrome is 3 where as it was 4 for alum, stannous chloride and ferrous sulphate.

The results (Table 5) indicates that colour fastness values to washing was good to very good with no/ negligible staining in case of alum, ferrous sulphate and chrome. 
Table.1 Specifications of the fabric

\begin{tabular}{|c|c|c|c|c|}
$\begin{array}{c}\text { Weave of the } \\
\text { fabric }\end{array}$ & \multicolumn{2}{|c|}{ Fabric count } & $\begin{array}{c}\text { Weight } \\
\left(\mathrm{g} / \mathrm{m}^{2}\right)\end{array}$ & $\begin{array}{c}\text { Thickness }(\mathrm{mm}) \text { at } \\
0.15 \mathrm{~g} / \mathrm{mm}^{2} \\
\text { pressure }\end{array}$ \\
\cline { 2 - 5 } & $\begin{array}{c}\text { Warp } \\
\text { ends/sq. inch }\end{array}$ & $\begin{array}{c}\text { Weft } \\
\text { picks/sq. inch }\end{array}$ & 60 & 0.32 \\
\hline Plain & 118 & 88 & 60 &
\end{tabular}

Table.2 Dye Absorption of Jangali Pyaz on Tassar silk at different concentrations

\begin{tabular}{|c|c|c|c|c|}
\hline $\begin{array}{c}\text { Dye } \\
\text { concentrations } \\
(\mathrm{g})\end{array}$ & $\begin{array}{c}\text { Absorbance } \\
\text { before dyeing (a) }\end{array}$ & $\begin{array}{c}\text { Absorbance } \\
\text { after dyeing } \\
(\mathrm{b})\end{array}$ & $\begin{array}{c}\text { Absorbance of } \\
\text { dyeing } \\
\mathrm{c}=\mathrm{a}-\mathrm{b}\end{array}$ & $\begin{array}{c}\text { Percentage dye } \\
\text { absorption } \\
\mathrm{p}=\mathrm{a}-\mathrm{b} / \mathrm{a} \times 100\end{array}$ \\
\hline 1 & .404 & .346 & .058 & 20 \\
\hline 2 & .803 & .661 & .142 & 35 \\
\hline 3 & .889 & .645 & .244 & 40 \\
\hline 4 & 1.566 & .907 & .559 & 47 \\
\hline 5 & 1.237 & .903 & .336 & 47 \\
\hline
\end{tabular}

Table.3 Dye Absorbpion of Jangali Pyaz on Tassar silk at different extraction times

\begin{tabular}{|c|c|c|c|c|}
\hline $\begin{array}{c}\text { Extraction time } \\
\text { minutes }\end{array}$ & $\begin{array}{c}\text { Absorbance } \\
\text { before dyeing } \\
\text { (a) }\end{array}$ & $\begin{array}{c}\text { Absorbance } \\
\text { after dyeing } \\
\text { (b) }\end{array}$ & $\begin{array}{c}\text { Absorbance of } \\
\text { dyeing } \\
\mathrm{c}=(\mathrm{a}-\mathrm{b})\end{array}$ & $\begin{array}{c}\text { Percentage dye } \\
\text { absorption }\end{array}$ \\
\hline 30 & .537 & .363 & .174 & 32 \\
\hline 45 & .665 & .315 & .350 & 52 \\
\hline 60 & 1.566 & .483 & 1.083 & 69 \\
\hline 75 & 1.037 & .413 & .624 & 60 \\
\hline 90 & .879 & .594 & .285 & 32 \\
\hline
\end{tabular}

Table.4 Dye Absorption of Jangali Pyaz on Tassar silk at different dyeing times using optimum concentration and extraction time

\begin{tabular}{|c|c|c|c|c|}
\hline $\begin{array}{c}\text { Dyeing time } \\
\text { (minutes) }\end{array}$ & $\begin{array}{c}\text { Absorbance } \\
\text { before dyeing }\end{array}$ & $\begin{array}{c}\text { Absorbance } \\
\text { after dyeing }\end{array}$ & Absorbance & $\begin{array}{c}\text { Percent dye } \\
\text { absorption }\end{array}$ \\
\hline 30 & 1.566 & 1.001 & .565 & 36 \\
\hline 45 & 1.566 & .916 & .650 & 41 \\
\hline 60 & 1.566 & .875 & .691 & 44 \\
\hline 75 & 1.566 & .828 & .738 & 47 \\
\hline 90 & 1.566 & 1.006 & .560 & 35 \\
\hline
\end{tabular}


Table.5 Colour fastness properties of samples dyed with Jangali Pyaz

\begin{tabular}{|c|c|c|c|c|c|c|}
\hline $\begin{array}{c}\text { SI. } \\
\text { No. }\end{array}$ & Mordant & $\begin{array}{c}\text { Light } \\
\text { Fastness }\end{array}$ & \multicolumn{2}{|c|}{ Washing Fastness } & \multicolumn{2}{|c|}{ Rubbing } \\
\hline & & $\begin{array}{c}\text { Colour } \\
\text { change }\end{array}$ & $\begin{array}{c}\text { Colour } \\
\text { staining }\end{array}$ & \multicolumn{2}{|c|}{ Fastness } \\
\hline 1 & & & & & Dry & Wet \\
\hline 2 & Control & 5 & $4 / 5$ & $4 / 5$ & 4 & $3 / 4$ \\
\hline 3 & Alum & 5 & 4 & 4 & 4 & $3 / 4$ \\
\hline 4 & Stannous chloride & 4 & 3 & 4 & $3 / 4$ & $3 / 4$ \\
\hline 5 & Ferrous sulphate & CI & 3 & 4 & $3 / 4$ & $3 / 4$ \\
\hline 6 & Copper sulphate & CI & $3 / 4$ & $3 / 4$ & 4 & 4 \\
\hline
\end{tabular}

CI- Colour increase

Table.6 Colour measurement and shade obtained with jangli pyaz dyed samples

\begin{tabular}{|c|c|c|c|c|c|}
\hline Mordant & $\begin{array}{c}\text { Shade } \\
\text { obtained }\end{array}$ & K/s value & $\mathbf{L}^{*}$ & $\mathbf{a}^{*}$ & $\mathbf{b}^{*}$ \\
\hline Control & Candy pink & 27.80 & 54.02 & 20.977 & 9.191 \\
\hline Alum & Dark pink & 35.01 & 54.02 & 3.019 & 8.823 \\
\hline $\begin{array}{c}\text { Stannous } \\
\text { chloried }\end{array}$ & Peach & 22.08 & 9.628 & -1.563 & 21.692 \\
\hline $\begin{array}{c}\text { Ferrous } \\
\text { sulphate }\end{array}$ & Steel grey & 28.33 & -0.221 & -19.442 & -0.154 \\
\hline $\begin{array}{c}\text { Copper } \\
\text { sulphate }\end{array}$ & Light brown & 23.04 & 5.370 & -14.339 & 8.140 \\
\hline Chrome & Dark candy & 38.17 & -4.749 & 8.048 & 0.760 \\
\hline
\end{tabular}

Table.7 Trace elements in (ppm)

\begin{tabular}{|c|c|c|c|c|c|}
\hline Detail & Zinc & Copper & Iron & Manganese & Lead \\
\hline $\begin{array}{c}\text { In the dye } \\
\text { (Jangali pyaz) }\end{array}$ & 20.0 & 5.5 & 234.2 & 2.15 & .08 \\
\hline
\end{tabular}




\section{Development of Shade with Different Mordants}

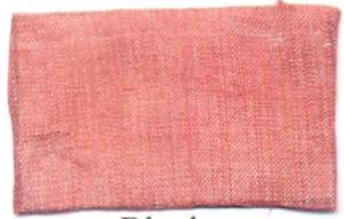

Blank

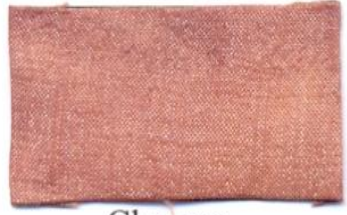

Chrome

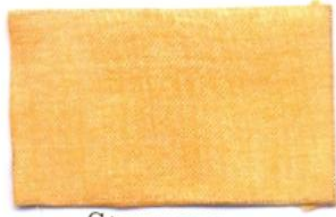

Stannous

Chloride

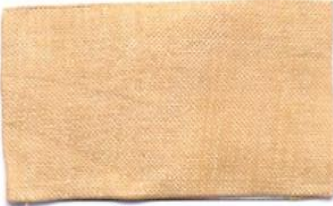

Copper

Sulphate

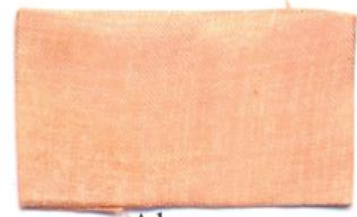

Alum

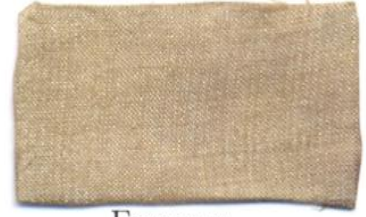

Ferrous

Sulphate

Dress dyed with Jangli Pyaz
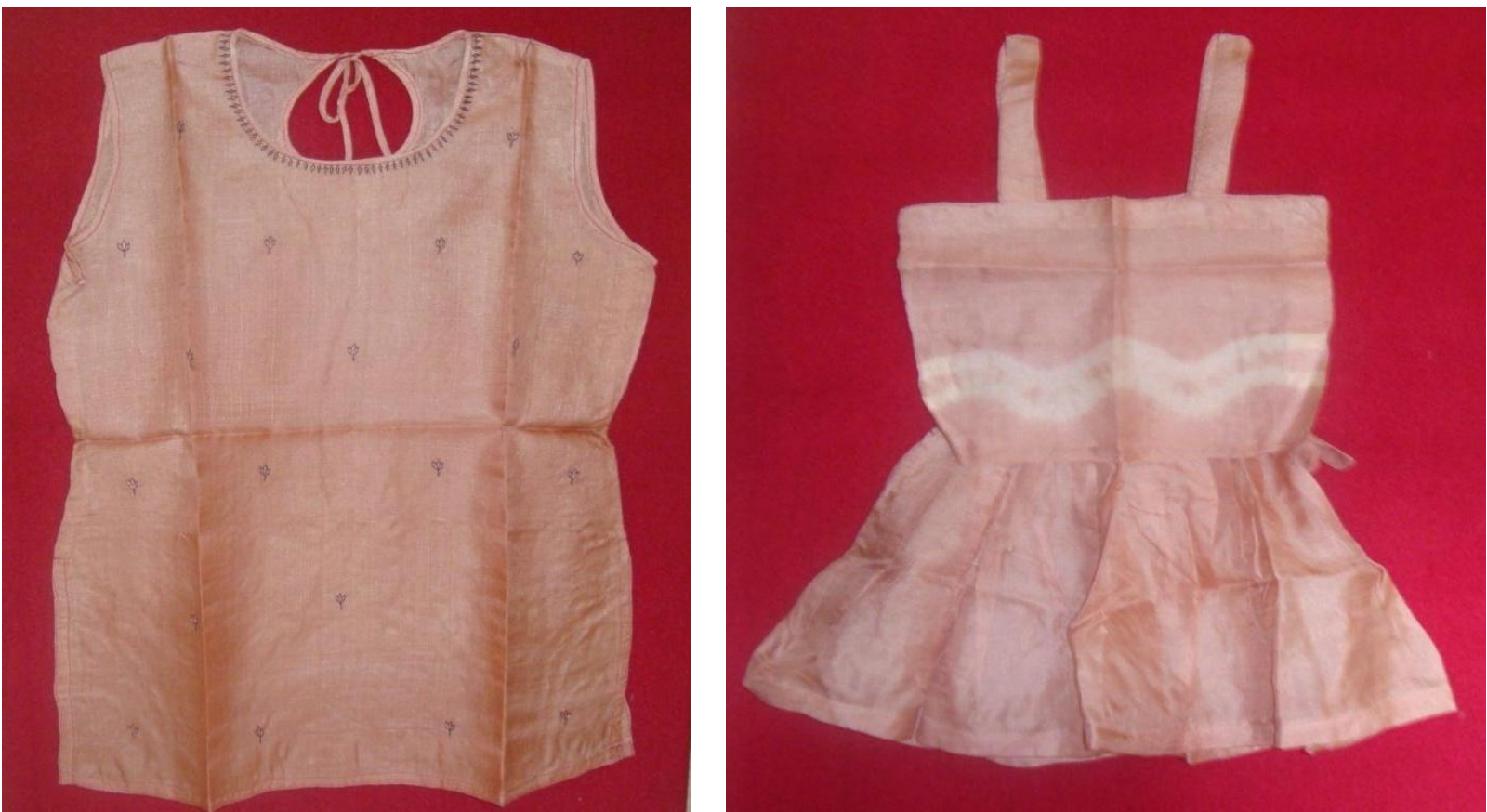


\section{Effect of mordanting method on production of shades with Jangli Pyaz on Tassar Silk}

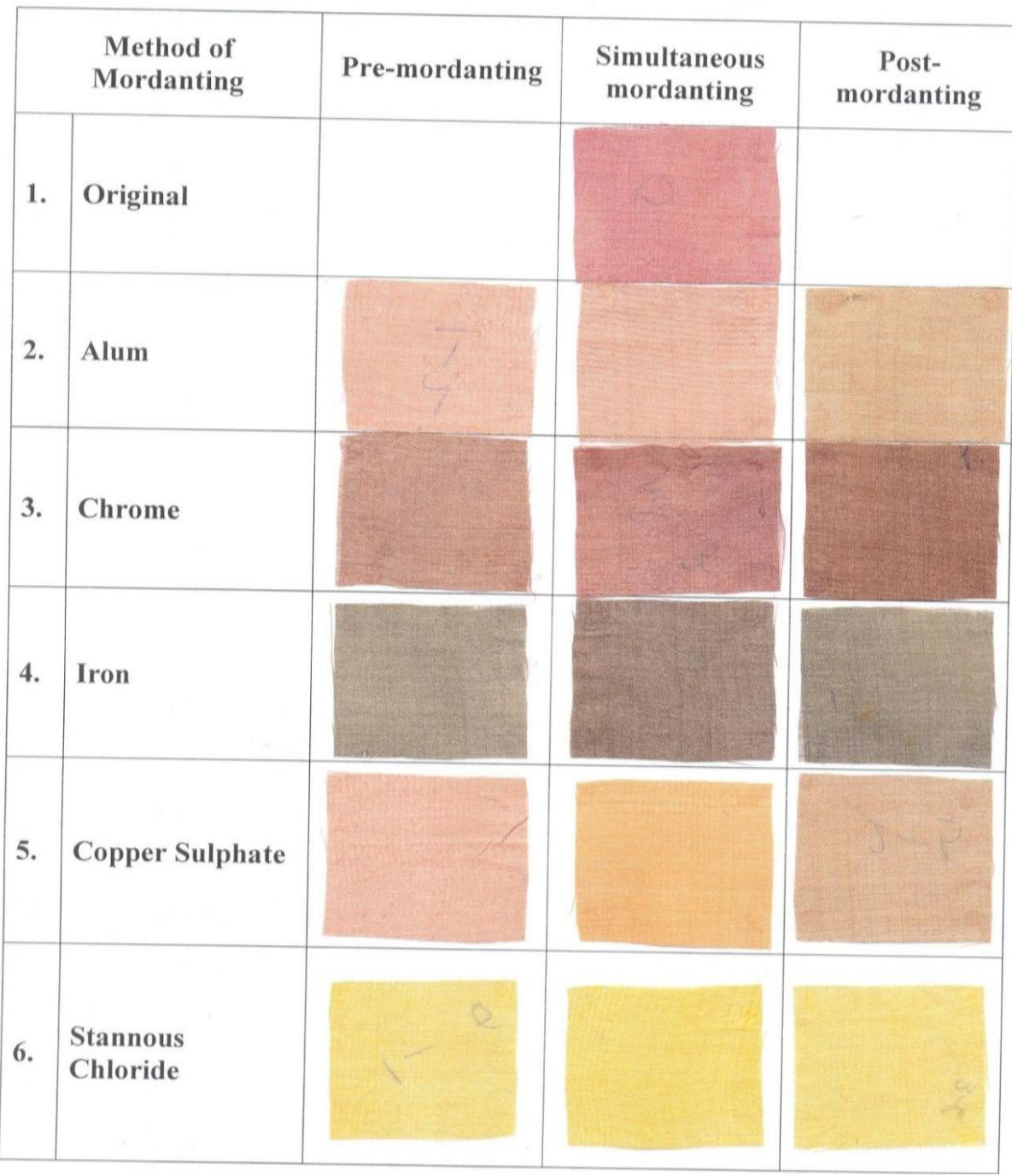
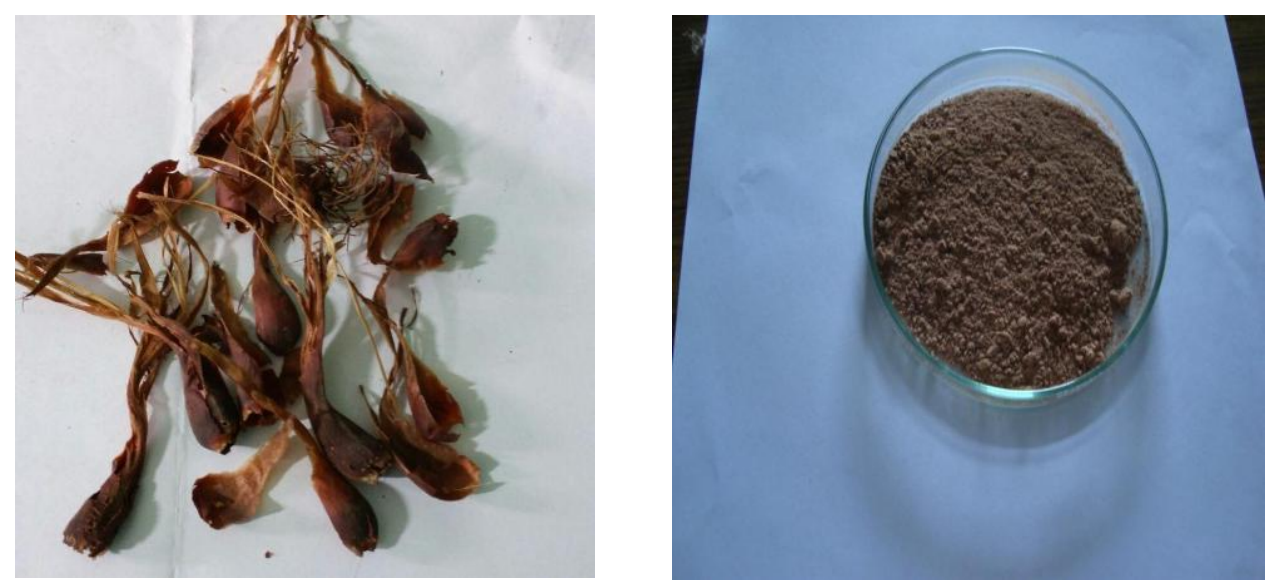

Natural dye source (Jangali Pyaz) 


\section{Rubbing fastness}

Rubbing fastness was carried out in dry and wet conditions. The test result given in Table 5 indicates that silk samples mordanted with alum, copper sulphate and chrome had very good fastness (4 and 3/4) under dry as well as wet conditions, while the fastness varied from 3to 4 rating under dry as well as wet conditions for stannous chloride and ferrous sulphate.

\section{Light fastness}

To determine the colour fastness to light, the colour change of the dyed samples were assessed against the grey scale and blue wool standards. The colour fastness to light of the silk dyed samples mordanted with alum, stannous chloride, ferrous sulphate, copper sulphate and chrome on is given in Table 5. Silk samples showed the fastness (change in colour) of 5 for samples mordanted with alum and without the use of mordant while the light fastness was observed as 4 in case of stannous chloride mordant.

Silk samples mordanted with chrome exhibited fastness of $3 / 4$. Thus it was concluded that tassar silk samples showed excellent light fastness properties for jangli pyaz dyed samples without mordant and with alum as mordant. It was good to very good in case of dyed samples mordanted with stannous chloride and chrome. In case of jangli pyaz dyed samples mordanted with ferrous sulphate and copper sulphate on tassar silk samples exhibited increase in depth of colour to sunlight may be due to photochemical change in dye molecules and phototropism.

All the sample dyed with jangali pyaz with different mordants showed fairly good to very good dry and wet rubbing fastness ratings ranging from $3-5$ on grey scale.

\section{Colour measurement}

The Tassar silk samples dyed with jangali pyaz mordanted with different mondants for production of shades were evaluated for colour uptake and $\mathrm{K} / \mathrm{s}$ values by using colour scan instrument. Table 6 shows the colour obtained and $L^{*}, a^{*}, b^{*}$ values for tassar dyed samples. $L^{*}, a^{*}, b^{*}$ is used for luminosity or lightness, redness and yellowness or blueness of the test specimen respectively. Positive $\mathrm{a}^{*}$ indicates more redness and negative $\mathrm{a}^{*}$ less red where as positive $b^{*}$ denotes yellowness and negative $b^{*}$ as blueness. $\mathrm{K} / \mathrm{s}$ value of the dyed fabric is the relationship between spectral reflectance ( $\mathrm{R}$ in $\%$ ) of the sample and its absorption (K) and scattering (S).

The colour gamut of Tassar silk samples dyed with jangali pyaz indicates a red yellow one and the metal complexes (mordants) shift the colour of the dye. The dyed samples ranged from light peach to candy pink and grey with different mordants. $\mathrm{K} / \mathrm{s}$ is the ratio of absorption coefficient $(\mathrm{K})$ versus the scattering co-efficient (S) for reflectance measurement. The greater the $\mathrm{K} / \mathrm{s}$ values, the greater is the intensity of the dyed sample. High K/s value of chrome (38.17) and alum (35.01) mordants showed greater intensity of colour, Dyed Tassar silk samples had very good colour strength and the dye had absorbed its maximum at the given wavelength.

The data indicates variation in $\mathrm{L}^{*}$ values, the maximum dark colour was obtained using ferrous sulphate $(-0.221)$ which indicates its dark colour (the lower the value darker the shade) the silk samples without mordant and with mordant alum has light values.

The L* values for other silk samples mordanted with stannous chloride, copper sulphate and chrome are 9.628, 5.370 and -4.749 respectively. Maximum redness was found in case of jangli pyaz dyed samples without the use of mordant i.e. $\left(a^{*} 20.977\right)$ followed by 8.048 with chrome mordant and it was 3.019 with mordant alum. Stannous chloride mordanted samples showed less redness $\left(\mathrm{a}^{*}=-\right.$ $1.563)$.

The maximum yellowness was obtained by using stannous chloride as a mordant $\left(b^{*}=\right.$ 21.692). The minimum yellowness was 
obtained in chrome mordanted samples ( $\mathrm{b}^{*}$ $=.760$ ). Moderate yellowness was indicated in alum $\left(b^{*}=8.823\right)$, copper sulphate mordant $\left(b^{*}\right.$ $=8.140)$ respectively.

Stannous chloride mordanted samples showed less redness $\left(\mathrm{a}^{*}=1.563\right)$ and more yellowness $(b * 21.692)$ whereas ferrous sulphate mordanted samples showed blues $\left(b^{*}=-0.154\right)$ with dark shade and less redness $\left(a^{*}=-19.442\right)$ as indicated by data shown in Table 6 .

\section{Trace elements}

Table 7 showed that contents of copper, zinc, lead and manganese were below the stipulated limit, it showed that the natural contaminants were low and so it can be used safely as ecofriendly for textiles.

\section{Effect of mordanting method on production of shades}

Variation in shades was found dyed with jangali pyaz using different mordants with different mordanting methods. Methods of mordanting has certainly affected the dyeing.

In simultaneous mordanting jangali pyaz produced beautiful shades of peach to grey. Ferrous sulphate and copper sulphate produced dark shades of grey and light brown respectively.

In pre-mordanting the shades were lighter.

In post mordanting, ferrous sulphate produced dark grey and all the shades were slightly darker in post mordanting method as compared to simultaneous mordanting. Stannous chloride produced yellowish peach in all the methods of mordanting.

Value added eco-dyed products like cushion cover, kids wear, jeans top, shawls, scarves were produced and were liked by many for its colour shades.

Jangali pyaz commonly known as vanpyaz (Asphodellus tenufolium) is a weed plant which shredded off as a waste, can be exploited as a source of natural dye for Tassar silk dyeing ranging from light peach to candy pink and grey depending upon the choice of mordants. Study was carried out to optimise the conditions of dyeing and it was found that in acidic medium dye yield was more which produced darker shades. Fastness to washing, light and rubbing was good.

\section{References}

Deo, S., 2010. Dye extracted from natural source- Spathidia flower, Asian Dyer, 7(3) 57-59.

Gulrajani, M.K. (1999) Present status of natural dyes, Colourage, 46(7): 19-28

Katyayini V.K.I.T. and Jacob, M (1998) Dye from mesta calyx, Indian Textile Journal, 108(1): 87-90

Rose, N.M. Khanna S. and Singh, Jeet S.S. 2007, Dyeing with natural colouring material - Geranium bark, Textile Trends. XLIX (196): 31-33.

Sarkar S.R. and Deo, S., 2012, Antimicrobial natural dyeing on cotton dress material, Asian Dyer 9 (2): 28-41.

Sarkar S.R. and S. Deo (2010) Dyeing Tassar silk with Parthenium hysterophorus solution to weed management, Textile Trends LII (10): 36-38.

Sunita, Kale, Sangita Naik and Suchita Deodhar (2010), Dyeing Paithani silk sarees with natural colours. Indian silk 48 (8): 24-26.

Tiwari, V., Ghorpode, B. and Vankar, P.S. (2001), Asian Textile Journal February $68-70$.

\section{How to cite this article:}

Sangeeta Deo, Smriti Rekha Sarkar and Savita Kumari. 2018. Extraction and Optimization of Natural Dye from Asphodellus tenufolium. Int.J.Curr.Microbiol.App.Sci. 7(11): 1355-1366. doi: https://doi.org/10.20546/ijcmas.2018.711.158 